\title{
Linguosynergetic potential of the pedagogical workshop
}

\author{
Natalia Sumina ${ }^{1, *}$, Anna Belozerova ${ }^{1}$, and Anastasia Evsenkova ${ }^{1}$ \\ ${ }^{1}$ Don State Technical University, 344003, Gagarin sq., 1, Rostov-on-Don, Russia
}

\begin{abstract}
The article reveals the linguosynergetic basis of the pedagogical workshop technology in teaching language and speech. This technology was tested within the educational project of the Don State Technical University (Children's University). The pedagogical workshop is interpreted as a technology for enhancing the speech, thought and language activity of students and also as a complex system with all synergistic properties. The stages of the pedagogical workshop are described using linguistic synergetic terms. The technological map of the workshop "Law Above All" is presented on the example of working with film text (the animated film "Prince Vladimir"). The following logic of work on the speech development is proposed: from a word to a phrase, a sentence and, more broadly, a text. The ways of activating the speech-thinking activity of students are formulated: the method of associations, drawing up reference schemes, the mechanism of predication. The conclusion is made that the systematic and holistic approaches to the methods of teaching language and speech are fully embodied in the pedagogical workshop.
\end{abstract}

\section{Introduction}

Specialists in the field of education and psychology state that a generation of children is currently growing up whose parents do not know in what world their children will live. Complexity and high instability of the surrounding space determines the crisis state of modern education: we do not know what to teach children, what future holds for the younger generation. It is obvious that modern education can no longer represent a simple knowledge, skills and abilities transfer.

In this regard, it seems to us that the linguosynergetic paradigm, being the basis for teaching language and speech, holds a powerful explanatory and heuristic potential, because it studies systems in dynamics, proposes a strategy for managing catastrophic processes, allows tracing the influence of the communicative environment on the content of speech work. The new general scientific synergetic paradigm offers a "program of a "new synthesis" capable of removing contradictions not only between humanitarian and natural science knowledge, but also between "two cultures" [1].

The objectives of the article are: 1) description of the linguosynergetic basis of the technology for activating thinking and teaching speech - a pedagogical workshop; 2) clarification of the mechanism for translating internal speech into external.

\footnotetext{
* Corresponding author: natalia.sumina@rambler.ru
} 
For this, a number of tasks should be solved: 1) describe the stages of the pedagogical workshop using the linguosynergetic paradigm; 2) introduce a technological map of a specific lesson, built on the principles of a pedagogical workshop; 3) formulate ways of activating students' speech-thinking activity in a lesson built in the technology of a pedagogical workshop, taking into account the linguosynergetic method.

The relevance of the study is predetermined by the need for a theoretical understanding of the linguosynergetics achievements as a new scientific paradigm.

\section{Materials and methods}

We believe that the main goal of teaching the Russian language is the development of speech, as well as the activation of the speech-thinking activity of students. We agree with the point of view of S.K. Gural [2], that the method of working with speech and language is determined by our knowledge of language and speech. The linguosynergetic view of language as a super-complex system, capable of self-regulation in conditions of intensive communication, social cognition and game decision, seems to be correct.

Within the framework of the of the Don State Technical University (Children's University) educational project the technology of enhancing the speech, mental and language activity of students was tested - the pedagogical workshop. The method of work described by us is actively used by A.V. Belozerova in the process of implementing the author's program for the development of oral and written speech "Russian soul reflection in the linguistic picture of the world" [3-6]. In our opinion, the use of the pedagogical workshop technology is justified, because this technology has many synergistic properties. The pedagogical workshop assumes the equality of all participants; co-creativity of a master (teacher) and a student, the result of which is the creation of oral and written works in different genres.

The pedagogical workshop is a specific communicative event in pedagogical discourse. The participants have an idea of this communicative event - the mental model of the pedagogical workshop is reflected in their minds. This model contains multidimentional information about the goals of the discourse, about its communicative acts and about the characteristics of the audience. The technology of the pedagogical workshop in the lessons of speech development creates a completely different context for acquiring knowledge students, while learning, are aware of the learning process, have the opportunity to feel the very path of obtaining knowledge. The discourse of the pedagogical workshop is aimed at creating interpretations, at the emersion of personal meaning during an intensive dialogue. It is important that the meaning of the word is not given in a finished form, but is born in the course of intensive communication. The acting person - the linguistic person - is both an observer, a meta-observer, and an interpreter.

The pedagogical workshop contributes to the development of a new type of thinking the so-called complex (non-linear) thinking, participating - along with imagination, feelings and affects - in the creation of a unified cognitive field.

Working according to the program using the pedagogical workshop technology, in our opinion, contributes to the creation of a non-judgmental environment that allows its participants to express themselves, without being afraid to make mistakes. Students offer several possible solutions to the problem without copying samples. The center of the educational process is the subject - subject relations, in which the teacher is not an indisputable authority, but appears as an equal partner who also participates in the process of finding a solution. The emphasis shifts from the result to the creative search process. This form of training creates conditions for each participant to approach the discovery of new knowledge and to gain new experience. Workshop participants can express themselves in any form: verbal, graphic, sign-symbolic, mixed. 
Let us present the main stages of the pedagogical workshop in their relation to linguosynergetic concepts.

1) The pedagogical workshop has an initial stage (inductor), which attunes its participants to joint activities in the educational process. At this stage, the association method can be used. Verbalized associations of the workshop participants confirm the research of linguists-cognitologists about the mental vocabulary presented in the mind of the wearer.

Associations show how the students themselves see their own thought, because a word in the mental lexicon exists in the aggregate of all connections with other units.

2) The next stage of the workshop - working with material, studying information in the process of creative interaction - involves the creation of a creative product, socialization, intermediate reflection and self-correction. In our opinion, this stage is consistent with such a property of complex systems as openness, understood as the readiness of all process participants for creative interaction during the study of information.

3) The culminating stage of the workshop is the stage of accessing new information. At this time, the creative product is being adjusted; correlation of the new with the previously mastered, leading to a gap between the existing understanding, representation of the surrounding reality and the emergence of new questions and hypotheses; advertising presentation of their projects, discoveries, texts. In our opinion, this stage of the workshop corresponds to the stages of chaos and bifurcation, when the system loses its stability and faces the choice of a different path of development. By interacting, the participants in communication form new meanings, and they also realize that there are just as many answers to many problematic questions (chaos). The task of the workshop participant is to make a choice (bifurcation point).

4) During the stage of reflection, which completes the pedagogical workshop, an analysis of what was passed and lived takes place. Participants analyze the received spiritual, moral and cognitive experience, realize their feelings, share their mood and attitude to the educational process. This stage is consistent with the stage of ordering the system. The ordering of the information received is carried out through the student's mental actions and consolidation in his linguistic consciousness "... knowledge about a conceivable conceptual image of the world based on the use of linguistic or non-verbal signs" [7].

Thus, in linguosynergetic terms, a pedagogical workshop can be described as a system that, on the one hand, has signs of reality (relative stability, functionality, hierarchy, which is understood as "the composite nature of higher levels in relation to the lower ones" [1]), on the other side - the properties of formation (nonlinearity, openness, instability, dynamic hierarchy, observability).

Nonlinearity implies the unpredictability of the system evolutionary development. Openness is the most important property - the ability of the system to interact with the environment, immersion in the context. As the system is nonlinear and open, then it is unstable. Dynamic hierarchy describes the nature of the bifurcation points passing by the system. The development of the system appears as an abrupt, suddenly emerging process. Observability is a dialogue between the inner observer (subject of cognition) and the metaobserver.

In our opinion, the pedagogical workshop, being built on linguo-synergetic principles, provides an "interdisciplinary synthesis" that overcomes the split between science and culture and uses a number of hybrid methods (systemic, semiotic, hermeneutic, cognitivediscursive).

In the process of implementing the speech development program "Russian soul reflection in the linguistic picture of the world", various types of pedagogical workshops are used: writing workshop, text / film text interpretation workshop, knowledge building workshop, value orientations workshop, etc. The division is very arbitrary and depends on several factors (the level of psychological state and age of the participants, their intellectual 
preparation, goals and time of classes are taken into account). However, any kind of workshop involves the following activities:

1. Creative exercises (imagine yourself as a participant in the creation of a feature / cartoon film and talk about your role in the creative process, write a new scene, justify its necessity).

2. Working with cognitive dictionaries of arts ("forms the recipients' understanding of the integral linguistic picture of the world") [8]. Cognitive dictionaries provide predicates - the basis for structuring sentences. Predicting the subject of thought is one of the most important stages of the mechanism for translating internal speech into external [9].

3. Oral and / or written works based on aesthetic and life impressions in different genre systems (writing reviews and responses about the script read, the movie watched; discussions about the director / cameraman's work, etc.).

4. Transformation of a non-verbal artistic image into a verbal image (an essay based on a film text). The task of expressing thoughts in writing in the form of a text-reasoning always causes difficulties, because plunges students into chaos. They face with the need to translate internal speech into external and find themselves at the point of bifurcation, because the possible content of an essay is represented in consciousness as a cognitive structure in the form of a nonlinear associative-verbal net; while the text is a sequentially unfolding construction. Students are aware of the contradiction between their endlessly developing and increasingly complex thoughts and the limitations of the language system, its resources. "The cognitive structures behind the word are fundamentally nonlinear and, in their linguistic embodiment, require special packaging" [1].

5. Translation of a verbal image into the language of another type of art (drawing up a continuation of the film / own script based on the work underlying the film text).

6. The embodiment of a creative product in a polycode text (it is known that a cinematic text is a kind of creolized text containing verbal and non-verbal signs). Students of the program have the right to choose the form of assignments, therefore, the result of their creative activity can be a media text created in the process of participating in the pedagogical workshop.

With the help of a film text or a text containing linguistic and cultural information, the workshop participants immerse themselves in the culture and life of the Russian people, comprehend the secrets of the native language, expand the lexical and grammatical stock, and develop communication skills (oral and written skills). The teacher is a guide, directing and supporting, giving the right to choose and the right to make mistakes, creating conditions for finding a possible adequate solution.

We will present a technological map of the pedagogical workshop "Law above all!" (on the example of working with the animated film "Prince Vladimir") [10] (see table 1).

The choice of this film text is not accidental: it immerses the workshop participants in the world of Slavic myths, in the traditions, customs and rituals of the Russian people (Slavic miracles), reflects the "cultural memory of the people, their mentality, the system of value orientations, national and cultural specifics", creates a "comfortable culture-consistent environment in the educational space, which contributes to a positive attitude of students, emergence of creative speech, which manifests itself in the creation of their own original products of speech activity", educates young people' "civic identity, an aesthetic attitude to the surrounding reality; forms moral principles and ideals, broadens cultural horizons "[11].

Table 1. Stages and Activities in the workshop

\begin{tabular}{|c|c|c|}
\hline $\begin{array}{c}\text { Stages of } \\
\text { the } \\
\text { workshop }\end{array}$ & Activity of the teacher-master & Workshop participants activities \\
\hline
\end{tabular}




\begin{tabular}{|c|c|c|}
\hline Induction & $\begin{array}{l}\text { Configures on collaboration on the topic of the } \\
\text { lesson, offering to watch a fragment of the cartoon } \\
\text { "Prince Vladimir" and answer the questions after } \\
\text { watching a fragment of the cartoon: Once upon a } \\
\text { time there lived in Ancient Russia wise magicians. } \\
\text { They knew the past and the future and taught } \\
\text { people how to live with the law... } \\
\text { The teacher invites the workshop participants to } \\
\text { answer the questions: who are the Magi, what did } \\
\text { they know, what is, according to the students, } \\
\text { "living by the law"? }\end{array}$ & $\begin{array}{l}\text { They answer the questions of the } \\
\text { master, express their assumptions, } \\
\text { hypotheses. } \\
\text { They perform vocabulary-stylistic } \\
\text { and grammatical work: they explain } \\
\text { the meanings of new words and } \\
\text { phrases, build new lexico-semantic } \\
\text { series for themselves. }\end{array}$ \\
\hline First stage & $\begin{array}{l}\text { Proposes to compose associative rows of the words } \\
\text { "law", "truth", "order" and to answer the question of } \\
\text { how these words are connected with good and evil. } \\
\text { The master again draws the listeners' attention to } \\
\text { the cartoon and asks to share their impressions and } \\
\text { describe the emotions and feelings that have arisen. } \\
\text { Questions after watching: 1. What are black deeds? } \\
\text { 2. What else should the student learn? 3. What does } \\
\text { the teacher's staff symbolize, why is it necessary to } \\
\text { make cuts on it for good deeds? } 4 \text {. Imagine and } \\
\text { draw an object that serves as a staff in your life. } \\
\text { Describe its magical capabilities. 5. What sacrifices } \\
\text { does the Magus warn about? } 6 \text {. Why is the law } \\
\text { above all? } \\
\text { The workshop participants were divided into groups } \\
\text { and offered to choose one question for reflection } \\
\text { and discussion: } \\
\text { 1. Images of Slavic mythology in the cartoon. } \\
\text { 2. A conversation between Aleksha and Boyan } \\
\text { about God, the meaning of the conversation for the } \\
\text { development of the plot. } \\
\text { 3. Songs and their role in the development of the } \\
\text { cartoon plot. } \\
4 \text {. Mastery of heroes' artistic embodiment (about } \\
\text { the production designer). } \\
5 \text {. The director's intention and its embodiment } \\
\text { When preparing answers, it is recommended to use } \\
\text { the cognitive dictionary of arts [9]. }\end{array}$ & $\begin{array}{l}\text { Share their thoughts that express } \\
\text { feelings, write them down on } \\
\text { separate sheets. Based on common } \\
\text { answers, they are combined into } \\
\text { groups. They draw magical } \\
\text { objects, describe them. They work } \\
\text { in groups. } \\
\text { In the process of working with } \\
\text { associative links, they name the } \\
\text { words and phrases that form the } \\
\text { lexical-semantic field "law": ruler, } \\
\text { peace, power, justice, good, God's } \\
\text { commandments (do not kill, love). } \\
\text { They study the entries of the } \\
\text { cognitive dictionary: artistic detail, } \\
\text { color, image, architectural image, } \\
\text { artistic image, harmony, } \\
\text { composition, space, line, contrast, } \\
\text { foreshortening, rhythm - with } \\
\text { special attention paid to the } \\
\text { predication mechanism. }\end{array}$ \\
\hline $\begin{array}{l}\text { Second } \\
\text { stage }\end{array}$ & $\begin{array}{l}\text { After watching the cartoon fragments (Prince } \\
\text { Vladimir, being deceived, kills his brother) invites } \\
\text { to answer the questions: } \\
\text { 1. How do you think the hero feels after the fight? } \\
2 \text {. Why do you think the prince is constantly } \\
\text { shrouded in fog in the cartoon? When does this } \\
\text { natural phenomenon become terrifying? 3. What } \\
\text { helps the prince to get out of the fog? 4. Why does } \\
\text { Boyan say that "the prince is at the edge"? Which } \\
\text { one? 5. Is it possible to interpret the dark and light } \\
\text { forces shown in the cartoon as different sides of the } \\
\text { prince's soul? Justify the answer. }\end{array}$ & They explain, share, write out \\
\hline Reflection & $\begin{array}{l}\text { Offers questions for reflection: } 1 \text {. Which stage of } \\
\text { the workshop was the most significant for you? } \\
\text { Why? 2. What feelings did you experience while } \\
\text { working? 3. What will you take with you after class } \\
\text { in your head, heart and hands? }\end{array}$ & $\begin{array}{l}\text { Analyze, re-read, listen to the } \\
\text { opinions of others, share their } \\
\text { thoughts. }\end{array}$ \\
\hline
\end{tabular}

After watching the animated film, the participants present the content of the film text in the form of a reference diagram reflecting the key meanings (see diagram 1). The concept words presented in the diagram, on the one hand, verbalize the mental actions of students in categorizing, conceptualizing the content of the cartoon, on the other hand, they are signals preparing the deployment of the subsequent hidden judgment. 
Joint commenting and interpretation of linguistic units presented in the diagram help to understand the fluidity of meanings. So, for example, the language sign fog is interpreted not only as a natural phenomenon ("opaque air saturated with water vapor or ice crystals" [12-16]. Film text and its intense interpretations actualize the figurative meaning of this sign ("about the state of obscurity, confusion of thoughts, representations "), which in turn generates meanings that flicker in the course of discourse - delusions, prejudices, selfdeception.

In the same way, the mobility, the fluidity of the meanings of linguistic signs, darkness, law, commandments, good tidings is realized.

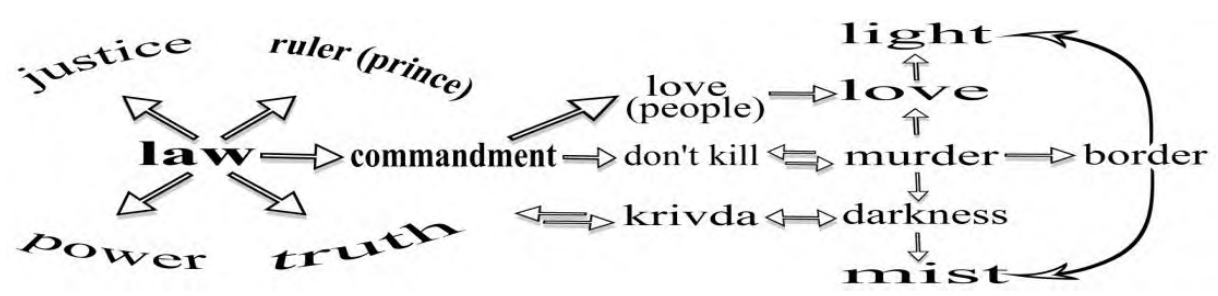

Fig. 1. Mind map

A kind of content generalization of the animated film is also the task to present any cartoon character, choosing two adjectives, three verbs to describe it, making one sentence and naming what feeling this character evokes in the workshop participant. In our opinion, this technique is very effective, because it is one of the intermediate mechanisms for translating internal speech into external (from a word through a phrase and a sentence to the text).

During the workshop, participants are asked to write a short essay: what does the expression "law above all" mean? Let's give an example of a mini-essay by one of the students:

Law above all

What are laws for? What is their purpose and meaning?

In human society, in various spheres of life, the accepted order and norms of behavior should be above all. This is necessary to avoid disagreements, for people to live in safety, be confident in their activities.

I believe that when a person has a concept of honor and justice, then no one will even think of breaking the law. Although the system of punishments keeps many people from committing crimes, and in a democratic society everyone is equal, unlawful actions against the individual (do not kill, do not testify), against property (do not steal), against the state are unacceptable.

If we do not follow the adopted laws, then there will be anarchy, chaos, fear in society, and this cannot be allowed. Therefore, I believe that the law is above all: honor and justice are always above greed and lawlessness. Everyone should follow the law. (Evgeny Nikolaenko, 2016-2017 academic year, first year of study).

\section{Results}

In accordance with the created program for speech development "Russian soul reflection in the linguistic picture of the world", the experiment was carried out in two groups: students from the speech development program from Children's University of DSTU (experimental group) and a group of schoolchildren of 5-8 grades from a secondary school took part in the work of the pedagogical workshop (control group). 
The purpose of the experiment is to determine the pedagogical workshop technology effectiveness for the development of speech. The results analysis obtained after the chosen methodology implementation showed the level of the communicative skills formation of the students who took part in the experiment. To obtain reliable results, we analyzed creative works (10 works in the experimental group and 10 works in the control group), and also observed the communicative activity of students during the workshop.

Let's present the results of the experiment in the table (table 2).

Table 2. Results and Criteria

\begin{tabular}{|l|l|c|c|}
\hline No. & Gained competencies & $\begin{array}{l}\text { Experimental } \\
\text { group }\end{array}$ & $\begin{array}{l}\text { Control } \\
\text { group }\end{array}$ \\
\hline 1 & Ability to perceive film text & $90 \%$ & $40 \%$ \\
\hline 2 & $\begin{array}{l}\text { Ability to express attitude to extra-linguistic } \\
\text { realities (ability to understand the feelings of } \\
\text { other workshop participants, to show empathy) }\end{array}$ & $100 \%$ & 100 \\
\hline 3 & $\begin{array}{l}\text { Ability to work independently and in a team } \\
\text { (without models and fear of making mistakes) }\end{array}$ & $100 \%$ & Not formed \\
\hline 4 & $\begin{array}{l}\text { Ability to express and argue your position } \\
\text { depending on the communicative task }\end{array}$ & $90 \%$ & $60 \%$ \\
\hline 5 & $\begin{array}{l}\text { Ability to reveal the topic and build the text in } \\
\text { accordance with the composition and logic }\end{array}$ & $80 \%$ & $70 \%$ \\
\hline 6 & $\begin{array}{l}\text { Ability to use visual and expressive means } \\
\text { Ability to present creative work in different } \\
\text { genres depending on the communicative task }\end{array}$ & $90 \%$ & $70 \%$ \\
\hline 7 & $\begin{array}{l}\text { Ability to improve what has been written } \\
\text { (creating a secondary text after intermediate } \\
\text { reflection based on new knowledge and taking } \\
\text { into account the opinions of classmates) }\end{array}$ & $100 \%$ & Not formed \\
\hline 8 & & \\
\hline
\end{tabular}

The work in the creative workshop of 20 students ( 10 people in the experimental and 10 people in the control group) was analyzed. The experiment showed that the participants' communicative competence was formed at a high level, among the students of the control group - at a satisfactory level, since the work with the film text caused difficulties. All participants of the experiment showed the ability to express empathy and understand the feelings of others, as well as to work in a team, but almost all members of the control group "waited" for templates and guidelines from the teacher, which contradicts the idea of the workshop, proposing equality of all participants in the educational process, the absence of an authoritarian leadership style and the co-creation of the teacher and students. The control group members were not ready for the situation of independent choice (bifurcation point), and they also experienced difficulties in editing creative works. Only the participants in the experimental group were able to improve what they wrote on their own: this type of work is performed by them in almost every lesson as part of the speech development program.

\section{Discussion}

The film text contributes to the appearance of a certain text-presentation in every workshop participant's minds of, a certain mental model of events that reflects the content of the cartoon. However, this model contains not only information from the film text, but also information of a different kind: various culturally delineated scenarios, ideas about wellknown episodes of social life, hypotheses about how culturally marked meanings arise in 
linguistic culture. The fluidity of meanings in the workshop course arises as a result of the joint interaction of many subsystems: the language system, the cinema text system, the system of intensive communications, subjects of language learning systems.

The word occupies a central place in the language system and, therefore, in the methodological structure of teaching language and speech. That is why we consider it appropriate to use the following logic in the work on the development of speech: from a word to a phrase, a sentence and, more broadly, to a text. This allows you to trace the moment of internal speech transition to external.

For the effective lessons organization using the linguosynergetic approach, we consider it important to observe the following methodological conditions: the teacher should promote the activation of the perception processes, analysis, interpretation using methods and techniques of a dialogical nature (dialogue of the cinema text level, dialogues of cultural eras level, dialogues of the texts from different forms of art level, dialogues of readers' discourses level). The result of this kind of dialogues is the speech, spiritual and moral development of students. All types of speech activity (listening, speaking, reading, writing) are activated.

The linguosynergetic approach in teaching language and speech also helps to implement the system of creative works and harmonize the works of art perception (this contributes to the deep development and expression of thoughts and feelings). The process of creating a new (own) text is presented to us as the establishment of new connections that receive verbal expression. The former connections of the cognitive structures of the thought process participants are regrouped.

\section{Conclusions}

The paper describes the linguosynergetic potential of the pedagogical workshops technology. The pedagogical workshop is presented as a system that has, on the one hand, relative stability, on the other hand, dynamic properties (nonlinearity, openness, instability, self-organization). The organization of the learning process with the help of a pedagogical workshop is based on the main principles: language and speech co-learning, language and culture co-learning; the teacher and students co-creation. The systemic and holistic approaches carried out in the pedagogical workshop influenced the choice of means, methods, techniques of teaching, as well as the formation of the linguistic, communicative and cultural competence of the participants in pedagogical communication.

An effective method of work on the speech development is recognized as the movement from word to phrase, sentence and then to the text. Speech-thinking activating methods are: associations, drawing up a reference scheme with keywords, working with cognitive dictionaries, which implements the predication mechanism.

\section{References}

1. Z. I. Komarova, Bulletin of PSLU, Language, linguistic system, linguistics in the mirror of synergetics, 4 (2012)

2. S. K. Gural, G. I. Petrova, V. M. Smokotin, Language and Culture, Expressing Inexpressible: Possibilities of Synergetic Efforts of Linguistics and Philosophy, 42 (2018)

3. A. V. Belozerova, Language. Communication. Culture. Collection of materials of the First International Scientific and Practical Conference of Young Scientists, Reflection of the Russian soul in the linguistic picture of the world (on the example of the 
program for the development of oral and written speech at the Children's University of DSTU), 168-171 (2017)

4. A. V. Belozerova, Dialogue of Cultures. Theory and Practice of Teaching Languages and Literatures: VI International Scientific and Practical Conference (October 9-11, 2018), Formation of national self-awareness of students of the Children's University in the process of working with a feature film, $104-107$ (2018)

5. A. V. Belozerova, Semantics. Functioning. Text: interuniversity collection of scientific papers, Author's program for the development of speech (from experience in the system of additional education), 161-166 (2019)

6. A. V. Belozerova, Scientific school of professor T.A. Ladyzhenskaya: materials of the scientific-practical conference, Communicative and cultural studies functions of Russian cinema in the classroom on the development of speech, 49-56 (2020)

7. L. P. Sychugova, Science. Innovations: XVIII Russian Scientific Conference, Lingvosynergetic approach to the self-development of language and speech activity of future language specialists (on the example of work on the methodology of teaching the Russian language), 827 (2018)

8. L. P. Sychugova, at al., Synergetic basis of author's educational, cognitive dictionaries. SHS Web of Conf., 69, 00017 CILDIAN-2019 Retrieved from: https://doi.org/10.1051/shsconf/20196900017 (2019)

9. L. P. Sychugova, Semantics., Functioning. Text, Predication as the most important link in speech production: methodological aspect, 220-225 (2016)

10. Animated film "Prince Vladimir" https://www.ivi.ru/watch/112673 (Last accessed 11.07.2020)

11. L. A. Khodiakova, Speech development methods of the creative school children in the culture context: theory and practice, 188 (2018)

12. S. I. Ozhegov, N. Yu. Shvedova, Explanatory dictionary of the Russian language: 80,000 words and phraseological expressions, 944 (1998)

13. T. I. Dombrovan, Research Journal of Drohobych Ivan Franko State Pedagogical University. Series 'Philology' (Linguistics), Linguosynergetics as a new direction of philological studies, 6 (2016)

14. D. Atkinson, Journal of Writing Research, Engaging in textbook writing as deliberate practice: How two expert ELT textbook writers use metacognitive strategies while working to sustain periods of deliberate practice, 11(3), 477-504 (2020) doi: xxx.

15. S. A. Crossley, Journal of Writing Research, Linguistic features in writing quality and development: An overview, 11(3), 415-443 (2020) 